\title{
0 que os adolescentes produzem de imagens? - Cultura visual, adolescências e educação
}

\author{
ANDERSON FERRARI
}

\section{Resumo}

O artigo é resultado de uma pesquisa de Iniciação

Científica realizada em quatro escolas na cidade de Juiz de Fora com alunos e alunas do segundo segmento do Ensino Fundamental, tendo como objetivo a investigação e problematização das relações que são estabelecidas entre os adolescentes e as escolas nas suas articulações com as imagens e o saber. Mais do que centrar na relação entre Cultura Visual, Educação e Subjetividades, o texto investe em novos objetivos e propostas de trabalho que dialogam com minhas atuações nos grupos de pesquisa e de estudo de gênero e sexualidade da UFJF. Neste sentido, estou interessado também nas relações desses adolescentes com as relações de gênero, sexualidades e imagens. Como as imagens educam nossos olhares para os gêneros e sexualidades?

Palavras-chave:

Cultura visual, educação, adolescências, gênero, sexualidade 


\title{
Visual Culture and the anthropological insight
}

\author{
ANDERSON FERRARI
}

\begin{abstract}
The article is the result of a survey of Undergraduate Research held at four schools in the city of Juiz de Fora with male and female students of the second segment of Elementary Education, with the aim of investigating and questioning the relationships that are established between young people and schools in their links to the pictures and learn. Rather than focus on the relationship between Visual Culture, Education and subjectivities, the text invests in new goals and work proposals that dialogue with my performances in the research groups and the study of gender and sexuality UFJF. In this sense, I am also interested in the relationships of these adolescents with gender relations, sexualities and images. As the pictures looks to educate our genders and sexualities?
\end{abstract}

Keywords: Visual culture, education, teens, gender, sexuality 


\begin{abstract}
A pergunta título deste artigo - O que os adolescentes produzem de imagens? - é o foco de uma pesquisa realizada em quatro escolas na cidade de Juiz de Fora com alunos e alunas do segundo segmento do Ensino Fundamental, tendo como objetivo a investigação e problematização do que é estabelecido entre os adolescentes e as escolas nas suas articulações com as imagens e o saber. Interessado nos processos de constituição dos sujeitos a partir da perspectiva de Michel Foucault (1988) nos seus jogos de força e negociação entre saber, poder e relação com o outro e consigo mesmo, a escola e, principalmente, o que acontece nas salas de aula, sempre esteve presente nas minhas preocupações de investigação. Nesta trajetória de pesquisa, fui alargando minhas análises, incluindo os jovens e suas relações com a cultura visual e com o saber, seja ele voltado para o conhecimento científico ou aquele que está direcionando a leitura, elaboração e entendimento e relação com as imagens. Partindo do pressuposto que somos uma sociedade imagética, quero problematizar quais conhecimentos são apropriados, construídos e ressignificados pelos jovens nesta relação com as imagens num processo de mão dupla. E, sendo fiel a minha trajetória de investigação, quero pensar essas problemáticas no campo das sexualidades, ou seja, como as imagens educam nossos olhares para as sexualidades e como as sexualidades dizem de imagens.

Cultura Visual, Adolescências e Educação. Três categorias de análise que dialogam e nos convidam a pensar como nossa realidade é construída, como vamos incorporando, convivendo, desconstruindo e reconstruindo imagens num processo inseparável entre imagens, ficção e realidade, de forma que podemos dizer que estamos constantemente interpretando e transformando o que chamamos de realidade. Trabalhar com
\end{abstract}


o que apareceu a partir dos alunos e alunas no interior das escolas pesquisadas é uma forma de olhar para as experiências que esses adolescentes estão vivenciando. Para Foucault (2004, 2009), a experiência está ligada aos processos de dessubjetivação. Se afastando da fenomenologia e das suas preocupações com o olhar reflexivo em busca das significações do vivido, o autor francês constrói a ideia de "experiência limite". "(...)a experiência é tratar de alcançar certo ponto de vista que esteja o mais próximo possível do não vivível” (CASTRO, 2009, p. 161). Algo que é capaz de arrancar o sujeito de si mesmo, fazendo-o desprender-se de si mesmo, de forma que ele não seja mais o mesmo. A dessubjetivação se constitui assim como forma histórica de subjetivação. Não há como separar uma da outra, e tampouco de separar a experiência como parte dessa relação, uma vez que ela se constitui nesta fratura entre dessubjetivação e subjetivação.

A sexualidade é um dos processos de dessubjetivação e subjetivação, o que nos faz considerá-la como um dispositivo (FOUCAULT, 1988), que envolve discursos, legislação, regras, imagens. Neste sentido, não há como separar sexualidade da cultura, que podem ser entendidas como processos educativos na medida em que vamos nos constituindo como seres detentores de determinadas sexualidades em meio a nossa cultura pelos modelos que entramos em contato performativamente. Assim, estou aproximando sexualidade e cultura visual de um entendimento de educação que está ancorado nesses processos de constituição dos sujeitos para além do campo escolar, centralizando as análises no cultural, ou seja, tanto por aquilo que ocorre nas escolas, quanto pelo que está em vigor no contexto social e cultural, buscando as condições de emergência entre os fatos, discursos, imagens a partir das interseções entre esses dois contextos e, deles, com a História. Por isso meu interesse pela Cultura Visual e seus desdobramentos no campo da Educação, nas escolas e na constituição das subjetividades. Mais especificamente estou apontando como principal problema a ser abordado neste artigo a relação entre os processos de constituição das subjetividades e das adolescências com a cultura visual. Como os adolescentes que estão nas escolas estão sendo chamados a produzirem imagens? Que imagens são produzidas pelos adolescentes na escola e para a escola? Que imagens são produzidas por adolescentes para além das escolas? O que essas imagens dizem das adolescências e sua relação com a Cultura Visual? Interrogações que, no seu conjunto, apostam mais na importância das perguntas do que na busca 
por respostas definitivas, me aproximando da perspectiva teórico-metodológica pós-estruturalista, uma vez que tomo essas categorias de análise como construções históricas e culturais, atravessadas por relações de poder-saber e implicadas nos processos de subjetivação que estão presentes também nas escolas. No campo das relações de gênero, sexualidades e imagens, as questões se desdobram numa única: como as imagens educam nossos olhares para os gêneros e sexualidades?

A Cultura Visual, como um campo de estudo que engloba um amplo conjunto de meios visuais para além das disciplinas acadêmicas (cinema, artes visuais, propaganda, história da arte etc), se aproximando de uma perspectiva interdisciplinar, se constitui como possibilidade de reflexão e problematização do que vivemos hoje como algo incerto, instável e contraditório, visto que vivemos em contextos sociais e históricos interpretados, simbólicos, de forma que o que fazemos e dizemos serão sempre discursos provisórios e temporais (HERNÁNDEZ, 2006). Isso chega e afeta a escola que, na sua tradição moderna disciplinar, apresenta dificuldades de lidar com as imagens, sobretudo aquelas elaboradas, trazidas e propostas pelos alunos e alunas, que acabam nos conduzindo a necessidade de rever as relações estabelecidas entre professores, professoras, alunos e alunas, entre esses e essas e o conhecimento, enfim, algo que nos conduz ao interior das escolas como um mundo de experiências que nos chama para novos modos de vida, novas formas de perceber, sentir e pensar o mundo e as escolas e a si mesmos. Após a coleta de dados, realizada por um questionário e grupo focal, nas quatro escolas - uma escola particular, outra pública estadual, uma terceira pública federal e a última pública municipal - é possível dizer que as imagens estão presentes cotidianamente nas escolas, independentemente das classes sociais que compõem esses espaços. Todos os alunos e alunas possuem celulares que tem como uma das possibilidades a de tirar fotografias e mesmo produzir pequenos filmes. Mais do que terem essa possibilidade a mãos, o que a pesquisa revelou é que efetivamente estão fazendo isso, ou seja, tiram fotos e filmam os amigos e a si mesmo, além do que ocorre no interior das escolas, mesmo que a escola não solicite algum trabalho com as imagens.

Esse é outro dado que a pesquisa demonstrou e que serviu como iniciativa para a escrita deste texto, ou seja, embora haja uma ligação constante entre alunos e alunas com as imagens, esses sujeitos, de forma geral, não identificam um trabalho 
desenvolvido pelas escolas. A exceção foi um fato que ocorre anualmente na escola pública federal, que é realizado como uma avaliação pela disciplina de Artes, que é uma mostra de curtas em que os alunos e alunas são chamados a produzirem imagens em grupos. Há alguns anos os professores de Artes dessa escola realizam uma "Mostra" de Cinema. Um evento ancorado na proposta curricular da disciplina que prevê para os anos finais do Ensino Fundamental o trabalho com as mídias. Limitada ao âmbito escolar e, mais especificamente, para os nonos anos do Ensino Fundamental, essa Mostra é estabelecida como atividade curricular de avaliação do trimestre e, portanto, como uma obrigação para todos. A proposta consiste na divisão em pequenos grupos ( 4 a 5 alunos) para a produção de curtas metragens. Cabe a cada grupo a elaboração de um roteiro (que é apresentado aos professores anteriormente), a preparação do material necessário, a filmagem, a edição e apresentação para os companheiros. Foram produzidos 16 curtas: A lenda de Blair, Deu a louca nos jogos mortais, $O$ Combate, A amiga invisível, Amor e Ódio, As ladras das meias pretas, Uma estranha mudou o meu dia, dentre outros. No entanto, no ano da realização da pesquisa um fato novo tornou esse evento diferente. O filme que segundo a avaliação das professoras deveria ganhar o primeiro prêmio era muito "pesado", trazia uma temática difícil de ser trabalhada na escola. Segundo as professoras, tocava em temáticas que não pertenciam às propostas curriculares das Artes. Intitulado "O mistério do estuprador" não deveria nem ser passado para os alunos, como argumentavam. Diante dessas colocações e do impasse entre a necessidade de se premiar ao mesmo tempo de censurar, as professoras não sabiam como lidar com essa obra produzida pelos adolescentes.

É esse filme que estou tomando como um convite para pensar as produções dos adolescentes no que se refere à Cultura Visual, aquilo que é trazido pelos alunos e alunas como problemática a ser discutida na sala de aula, como, por exemplos as questões de gênero e sexualidade e o processo educativo que está atravessado nestas relações e que estão presentes nas salas de aula. Mais do que isso, quero problematizar os desdobramentos desse vídeo no que se refere à apropriação e ressiginificação da proposta curricular por parte dos alunos e a introdução de dois aspectos que me parecem importantes presenças nesta produção que são a amizade e as homossexualidades. Eles foram capazes de realizar a atividade e ao mesmo tempo transgredir o que foi proposto, sugerindo novas 
discussões para além da produção audiovisual. Neste momento, invertem a situação e acabam propondo novas temáticas de forma que podemos pensar nesse movimento curricular que surge dos alunos de forma sutil.

\section{"O que a gente pode fazer agora é se unir" - A amizade em "O mistério do estuprador"}

A amizade é uma tônica em todos os filmes, seja na composição dos grupos para a realização da tarefa e que aparece no desenvolvimento dos curtas, ou como tema que atravessa a temática escolhida. Em o "mistério do estuprador" isso não é diferente. Desta maneira, quero tomar a noção de amizade a partir da perspectiva foucaultiana como um tema das preocupações do filósofo que apareceu na última etapa das suas produções no momento em que buscava definir a filosofia como estilo de vida e não como algo que dominamos e que nos "revelaria a verdade", ao mesmo tempo em que se voltava para a noção de ética, desvinculando-a da moral (ORTEGA, 1999). Em meio a esse projeto mais amplo, a amizade pode ser entendida como um meio institucional de atingir esses objetivos em torno dos novos estilos de vida e da ética. Dois termos - "amizade" e "institucional" - que, na compreensão de Foucault, se afastam dos sentidos que estão presentes no senso comum. Assim, a amizade não é entendida como envolvida nas compensações afetivas, tampouco o institucional diz dos códigos que nos tornam sujeitos e cidadãos nos regimes democráticos. Ambos tem a ver com a ética, com a ação dos outros sobre o "eu" assim como minha ação na condução dos processos de subjetivação que estou inserido e, mais do que isso tem a ver com as rupturas, com aquilo que rompe as fronteiras das morais e do que "está definido" e que são capazes de transformar os sujeitos. Neste sentido, a amizade como um meio institucional é a demonstração de que não existem regras e princípios universais e a priori, mas que em se tratando de escolas, isso é algo construído constantemente em meio às relações entre os sujeitos.

A partir dessas primeiras ideias podemos pensar na proposta das professoras de Arte em torno desta produção dos curtas pelos alunos e alunas. Uma ação que surpreende os alunos e as alunas e marca suas trajetórias na escola, de forma que são capazes de lembrar da "novidade" quando perguntados sobre o trabalho com imagens nas escolas. Ao serem perguntados sobre o que acharam de tal proposta as respostas nos convidam a pensar os resultados para além dela em 
si, mas na articulação entre os sujeitos: "muito legal porque a gente se divertiu e nem notamos que era uma prova"; "é maior chato fazer trabalho com livro, é legal assim junto com os amigos, em casa, com música, foi maior legal”; "deu um trabalhão mais foi legal". Os professores foram capazes de trabalhar com as imagens a partir de um argumento curricular, assumindo as temáticas que fazem parte do currículo da disciplina de Arte para os nonos anos do Ensino Fundamental, ao mesmo tempo em que mantiveram um espaço de liberdade e de prazer para que os alunos e alunas pudessem propor algo a partir deles. Afrouxaram a fronteira entre o que é ou deve ser proposto pela disciplina e pelas artes visuais e que se constitui como regra e aquilo que surge dos alunos. Apostando nesta liberdade e espaço de criação dos alunos e alunas possibilitaram a transformação dos sujeitos, estilizando suas existências pelas imagens na presença do outro. No entanto, ao entrarem na proposta que não definia, de antemão, as temáticas possíveis, os alunos que produziram o "Mistério do Estuprador" trouxeram um roteiro em torno das sexualidades e dos gêneros, já que se trata do drama envolvendo 4 meninos sob a ameaça de um estuprador de meninos. O drama surpreendeu as professoras e rompeu com aquilo que elas acreditavam como conveniente para uma escola e para alunos e alunas desta faixa etária, fazendo-as se aproximarem das suas formações, das suas concepções de educação, de escola e de adolescências, de forma que esse "outro", tanto os alunos, quanto o curta, as imagens e a temática modificam a proposta e as professoras, num quadro relacional que demonstra a constante recriação de si, os que estamos envolvidos na escola. Minimamente o curta exerce um papel próprio do cinema que é a possibilidade de entrar em contato comigo mesmo e com aquilo que me constitui e me possibilita circular e ver o mundo e a mim mesmo a partir das imagens.

A amizade é algo percebido deste o início do curta. Ortega (1999) ao definir a amizade como "uma forma de subjetivação coletiva" nos incita a olhar o curta e dar lugar para esse tipo de provocação muito comum nas escolas que é a constituição de grupos para produzir imagens. Nem sempre a constituição de grupos numa sala de aula é tranquila. Uma vez ou outra enfrentamos questões que envolvem a exclusão de determinados alunos ou alunas que ficam sem grupo. Um grupo se constitui como tal na medida em que há ação de uns sobre outros dando forma coletiva a esses processos de subjetivação em que cada um vai constituindo imagens de 
si e dos outros, sendo uma forma de vida e de trabalho que permite a criação de espaços que chamam para o desafio de construírem e entrarem em contato tanto com necessidades individuais quanto com objetivos coletivos. Sendo um apelo à experimentação de novas formas de vida, individual e em grupo, a proposta de produzir um curta a partir da formação dos grupos dá movimento à turma e à escola e investe em algo pouco comum nas disciplinas e que o trabalho com as imagens possibilitam que é o contato com a fantasia, com a ficção ao mesmo tempo em que traz a potencialidade de se pensar e repensar as formas de relacionamento existentes em nossa sociedade e que nos constituem. Neste sentido podemos pensar o que faz quatro meninos adolescentes entre 13 e 14 anos produzirem um curta em que um estuprador de meninos é o tema para aproximar os outros em torno da amizade. Ao serem questionados como construíram o roteiro, eles nos contam que a partir da proposta das professoras e da composição do grupo levando em consideração a aproximação afetiva dos quatro, um deles lembrou de uma notícia apresentada naquela semana num jornal local a respeito de um estuprador de mulheres. Com essa informação na memória, o aluno propôs ao grupo o deslocamento desta notícia de jornal para o gênero do cinema, de forma que pudessem produzir uma ficção em cima de um fato da realidade e que havia marcado o leitor, que ao revisitar suas memórias é capaz de retransmiti-la aos demais, que entram em contato com suas memórias e imagens que foram capazes de construírem sobre estupros ao longo de suas trajetórias e educação imagética por filmes, telenovelas e reportagens e, coletivamente, escrevem uma narrativa de estupro pelas imagens. Levando em consideração esse fato, "O mistério do estuprador" pode ser classificado como um curta que tem um roteiro estruturado, com cenas bem gravadas e com a utilização de estruturas comuns nos filmes de suspense, comédia e terror a partir das memórias, experiências visuais e narrativas de estupros dos meninos, que são trazidas para o grupo para construírem algo próprio. Imagens que geram imagens. Ao acessarem suas memórias podemos pensar como foram educados visualmente para compor imagens de estupros, em que momentos aprenderam como representam cenas de estupro de forma que são capazes de construir um vídeo como fizeram. É possível perceber que os meninos incorporaram a organização desses estilos de filmes, sabendo utilizar a música, os cortes, os diálogos e silêncios, a movimentação 
da câmera, resultando num desenvolvimento organizado da história. Enfim, também demonstram que foram educados pelos gêneros do cinema. Ao realizar a tarefa exigida estão falando de si, estão demonstrando como somos educados pelas imagens e como isso vai nos constituindo e dando um sentido para o que chamamos de "realidade".

A primeira cena que faz a introdução da trama é construída com um menino adolescente falando ao celular, no estacionamento de um prédio, tendo ao fundo uma música. Mas não uma música qualquer. Trata-se de um rap com uma batida forte e volume alto, criando o clima de ação e com a seguinte letra: " $E$ nóis, pode crer, pode crer, estilo mineirinho, tá ligado? tá ligado? (...) o asfalto me criou, mas a favela me adota... nada importa quando eu fecho a porta, apago a luz e faço tudo que ela gosta: calor, suor, clima de amor, sexo selvagem, perda do pudor, nossa relação se resume a ralação do joelho, do chão... Uma letra com apelo social, que já fornece, de imediato, a vinculação do que iremos encontrar com sendo uma questão dessa ordem. $\mathrm{O}$ adolescente caminha e, aparece pela primeira vez, um personagem mascarado que o vigia de longe ao mesmo tempo em que segue sua trajetória. Cena rápida de perseguição que termina no primeiro ataque, revelando essa personagem como sendo o estuprador, mesmo porque se diferencia ao utilizar máscara, criando um clima de suspense. Para construir esse primeiro ataque, os meninos posicionam a câmera tendo um carro como obstáculo, de maneira que só podemos ver os braços num movimento de levantar e abaixar, caracterizando o que conhecemos como uma abordagem em que a vítima tenta se defender. Há o primeiro corte em que aparece o título do filme. O corte é um momento importante para o trabalho com as imagens. Podemos pensar que as imagens se articulam entre dois aspectos - o político e o poético - dois aspectos que negociam e se relacionam neste processo que vai das imagens ao observador. O político seria os discursos presentes nas imagens e mesmo os discursos que as imagens produzem. No entanto, há um espaço entre o que está na tela, na televisão e aqueles e aquelas que estão assistindo e sendo chamado para a trama. Esse espaço que vai da tela ao observador é um espaço do vazio, um espaço de liberdade em que é o observador que preenche. Ao preencher esse espaço, não é mais o filme, o curta enfim, não são mais as imagens que estão falando, mas o próprio observador e suas memórias, trajetórias pessoais, experiências, a cultura. Esse espaço do vazio e de liberdade em que o expectador é chamado a preencher é o aspecto poético das imagens. 
O curta se organiza em torno de duas lógicas. Um em que os integrantes se afastam em situações em que ficam isolados e assim vulneráveis aos ataques, algo típico dos filmes de suspense. E outros momentos em que se encontram e se unem para enfrentar a ameaça e o perigo e mesmo construírem a ameaça e o perigo em que a amizade com ação de uns sobre os outros nos processos de transformação dos envolvidos é o que atravessa esses encontros. O primeiro diálogo já diz desse sentido de amizade como algo inquietante e perigoso (ORTEGA, 1999), ao mesmo tempo que inesperado e intenso.

- Estuprador aqui no prédio.

- Eu tenho medo, eu vou embora.

- Não irmão, tem que ter muito cuidado.

A notícia causa susto e preocupação. Ao mesmo tempo ela serve para criar aproximação e cumplicidade entre eles, que parecem se unir mais para se proteger. Essa ideia vai se desenvolvendo ao longo do filme na medida em que os estupros vão atingindo cada um deles. Os meninos atacados são socorridos pelos outros, que demonstram atitudes de companheirismo e solidariedade. Em uma dessas cenas o menino estuprado é encontrado no elevador, agachado e chorando, e é amparado, com o seguinte diálogo: "Cássio!!!! O que aconteceu, amigo? O que aconteceu? Vamos para casa, vamos para casa, amigo!!! (...) Calma, Cássio. Você vai ficar bem, amigo.” Foucault (1984) traz de volta o caráter subversivo da amizade e mais do que isso, investe nesta subversão como uma forma de deslocar os sujeitos das suas identidades congeladas entre o público e o privado. Comumente as questões de sexualidade, sobretudo em se tratando de um drama envolvendo estupro é algo tratado no campo do privado. Esses alunos subvertem essa relação trazendo para o público algo que não esperamos, algo do privado. Talvez isso, ou seja, esse rompimento da fronteira entre o privado e o público que envolve a construção das sexualidades, tenha sido a grande dificuldade dos professores em lidarem com essa produção e passá-la aos demais. Essa produção poderia detonar um processo de discussão entre os alunos e alunas que seria uma ruptura, uma novidade, o impensável que muitas vezes, nós professores preferimos evitar. A grande questão talvez seja essa que "O mistério do estuprador” incita, que é tornar pensável o impensável.

As sequências das cenas são estabelecidas pelos cortes, em que utilizam da tela escura com expressões tais como 
"no dia seguinte", "logo", "27 minutos depois", "2 semanas depois", estabelecendo uma linearidade. Além disso, elas seguem uma lógica muito comum nos filmes de suspense, em que cada personagem se distancia do grupo. Assim, cada menino acaba ficando isolado em algum momento da história e espaço do mesmo prédio, estabelecendo uma lógica que serve para constituir a narrativa de suspense. Intercaladas pela volta ao grupo, entramos em contato com duas situações de ataque. Primeiramente, um deles encontra o estuprador no elevador, seguido por um segundo ataque ocorrido no banheiro. Para causar a sensação de suspense adotam os mecanismos de focar a câmera no personagem que está sozinho sem abrir o ângulo, além da música num volume mais alto e o deslocamento dos personagens, ora com a imagem no estuprador ora no outro personagem, de forma que essas ações vão construindo um diálogo entre o menino sozinho e a possibilidade do estupro. Situações que misturam drama e comédia, como, por exemplo, a que o menino chega a casa em busca de banheiro e encontra o estuprador sentado no vaso sanitário que puxa-o para dentro do cômodo e fecha a porta. Não recorrem a situações de violência explícita. Isso fica por conta dos espectadores que ao pensar em estupro, relaciona-o a violência. Relação que é passada pela narrativa da produção, uma vez que os meninos choram, são consolados por outros, pedem justiça, enfim, reações típicas de quem sofreu algum tipo de agressão.

Os discursos utilizados revelam algumas questões importantes. Uma delas é a união do grupo, seja para amparar os que sofrem os ataques e mesmo para discutir o assunto. Buscam criar estratégias de proteção, discutem sobre justiça e concluem: "O melhor que a gente pode fazer agora é nos unir". Também aparece o discurso da prevenção. O menino que é atacado no elevador reclama, ainda mais preocupado, que o estuprador não utilizou camisinha. No ataque do banheiro, o estuprador sai com uma camisinha utilizada e mostra para a câmera. Ao final, conseguem perseguir e pegar o estuprador. Parece ser um final feliz e esperado por todos. Fugindo a esse clichê, surpreendem...

"Seis meses depois", o corte nos remete a uma cena que acontece pela primeira vez em outro espaço que não é o prédio, mas sim a biblioteca da escola. Encontrando um colega que está lendo o jornal, ficam sabendo que o estuprador está de volta. Na última cena, "saindo da Biblioteca", um dos meninos se encaminha para o banheiro e encontra novamente 
o estuprador, numa sequência em que esse sai da cabine do banheiro só de cuecas em direção a um novo ataque, se apropriando da lógica já estabelecida pelas outras cenas. Enfim, é uma produção com quatro atores e personagens, que utiliza duas locações (o prédio e a escola) e que se organiza a partir de recursos simples conseguindo cumprir sua função de passar para o expectador uma história. Não é um filme que tem um final. Ele termina exatamente deixando em aberto a história, uma vez que outro estuprador aparece, fazendo com que o debate se prolongue para além do filme na medida em que podemos dar continuidade e seguimento à cena e a história.

Saber que o curta poderia ser passado para os demais amigos e amigas de turma nos convida a pensar que os meninos que organizaram o vídeo investiam na ligação entre uma proposta individual e a subjetivação coletiva, como nos aponta Foucault (1984) como uma dos aspectos da amizade. A amizade é um convite à experimentação. Talvez possamos dizer que o "Mistério do Estuprador" só foi possível por se tratar de uma produção entre amigos e para amigos, o que possibilita experimentar algo novo, para o grupo daqueles que construíram o curta e também para os professores e para os demais alunos. $\mathrm{O}$ trabalho com imagens é ainda negligenciado no Brasil, como aponta Dias (2006), sobretudo no que diz respeito à experiência com o cinema e suas relações com gênero e sexualidade. Talvez por isso o trabalho proposto com a produção dos curtas tenha sido tão aberto, deixando um espaço de criação dos alunos e alunas que assim trouxeram para a escola, novas e diversas formas de conhecimento como outras formas de se constituírem como homens. São meninos que choram, que se abraçam, que demonstram a fraqueza diante da violência, que consolam um ao outro, enfim, nova sensibilidade e uma forma diferente de perceber as relações entre meninos e a realidade atravessada pelo cuidado. Eles trazem uma nova dimensão da amizade a partir do vínculo a outras formas de relação entre meninos e com o outro que passa pela escolha das afinidades e que podemos pensá-la como a cortesia (ORTEGA, 1999). Ortega no seu trabalho sobre a amizade e estética da existência em Foucault nos chama atenção que o seu estudo permitiu "compreender, entre outras coisas, as dificuldades que os homens têm, em contraponto com às mulheres, para introduzir uma dimensão da afetividade em suas relações de amizade, incapazes que são de ir além de uma 'palmada no ombro', o que representa, no fundo, um atrofiamento histórico" (1999, p. 26-27). Uma análise que torna "O mistério do estuprador" como o novo. 
Pouco a pouco a amizade entre homens foi se tornando um sentimento inquietante e perigoso, ao mesmo tempo, que inesperado e intenso e que, portanto, deveria ser afastado, controlado e codificado. Poderíamos pensar, como sugeriu Foucault, que a homossexualidade nasce quando não é mais permitida a amizade entre homens, de forma que a amizade sempre foi vista com um certo cuidado no Ocidente.

\section{A homossexualidade}

Outra questão que gostaria de trazer para discussão diz respeito à presença da homossexualidade na produção dos alunos. A primeira vista, o expectador poderia dizer que a produção dos alunos não trata de homossexualidade, tampouco ela é mencionada. Em nenhum momento é construído explicitamente discursos sobre a homossexualidade. No entanto, podemos pensar que ela está presente o tempo todo, seja na negação ou na relação que é estabelecida para a construção das masculinidades em torno da amizade. Ao elegerem essa temática do estupro de meninos, que é um tema tabu na sociedade, sobretudo na escola, esses meninos nos possibilitam entrar em contato com as representações de homossexualidades que foram construindo ao longo de suas trajetórias sociais e culturais. Em se tratando de um drama de meninos violados por um menino, nos chama atenção a ausência dos discursos das homossexualidades. E, neste sentido, podemos pensar que as homossexualidades estão na negação, algo muito comum em se tratando do que ocorre nas escolas, quando esta expressão da sexualidade ocupa o lugar do "não".

Ao construir a trama os alunos acabam trazendo para o nosso conhecimento os seus sentidos a respeito daquilo que estão representando, de forma que podemos pensar numa educação da cultura visual, ou uma educação a partir da cultura visual que nos convida a destacar as relações das imagens com o cotidiano que estimula a produção do curta. "O mistério do estuprador" nos ajuda a colocar em discussão a construção social da experiência visual, minimamente em torno do estupro e violência entre meninos, a amizade e a homossexualidade. Três aspectos que se articulam mutuamente nas suas construções. Ao ver as imagens uma questão que chama atenção foi à proximidade corporal e emocional destes meninos, algo pouco comum nas construções de masculinidade que ocorrem no interior das salas de aula, em que as aproximações dos meninos se dão a partir dos jogos de luta, disputa, brin- 
cadeiras violentas em que o limite do contato corporal está nos gestos agressivos e de pouca demonstração de afetividade. No entanto, algumas cenas fogem destas características o que em outras situações seriam suficientes para a classificação e a emergência de discursos das homossexualidades. No curta os meninos choram, se abraçam, se consolam, beijam as mãos, carregam o agredido nas costas, enfim, situações que na sala de aula serviriam para um comportamento de gozação e emergência das homossexualidades, visto que se aproxima de comportamentos tidos como femininos e pouco valorizados entre meninos. É inegável a relação entre as construções de gênero e sexualidades, de maneira que ao se aproximar daquilo que é considerado como algo de menina, os meninos sofrem outro tipo de enquadramento e classificação no âmbito das sexualidades, fazendo surgir as homossexualidades. Sabendo que a produção poderia passar para os demais alunos e alunas da sua sala podemos nos perguntar a respeito dessa mudança e mesmo do pouco receio em torno das homossexualidades, que também é uma questão importante para as suas construções e masculinidades, ou seja, as homossexualidades parecem "ameaçar" mais a meninos do que a meninas. Para a construção das masculinidades os meninos negam as feminilidades e as homossexualidades. Neste sentido, podemos nos questionar: o que faz esses meninos se arriscarem nesta produção em que existem outros tipo de afetividade entre eles sem o "medo" das homossexualidades? Uma das possibilidades de leitura da ausência da discussão e do medo em serem classificados de homossexuais poderia nos revelar sobre os sentidos que esses alunos atribuem as homossexualidades. Podemos pensar que para esses alunos não há homossexualidade e o discurso não é construído pela falta de desejo. Não há desejo nas relações, são situação de violação, de violência e de estupro entre meninos. O único que parece ter prazer é o estuprador. Como a trama gira em torno dos agredidos essa questão não está presente. Eles não têm desejo nas relações, não são situações de procura e afetividade. Parece que para esses meninos as homossexualidades estão diretamente ligadas ao desejo e onde não há desejo não há homossexualidades.

Esse tipo de raciocínio é fundamental para se pensar a criação da homossexualidade como objeto inventado pelo desejo. A construção das homossexualidades e, também, do "desejo homossexual" está servindo para que os meninos construam conhecimentos, discursos, representações e regras comuns de compreensão dessas realidades, fortalecidas através das 
relações entre eles e o reconhecimento emocional. Neste sentido, o curta inserido numa discussão mais ampla em torno da cultura visual nos convida a pensar como essas questões são transdisciplinares. Fazer a proposta em torno da produção de imagens e discursos, sem definir as temáticas, já é uma proposição que possibilita a transdisciplinaridade, uma vez que os alunos estão livres para escolherem aquilo que chama atenção deles, aquilo que é capaz de, ao ser produzido, revelar a construção social das suas experiências visuais, demonstrando o seu caráter fluído, sujeito a negociações, disputas, encontros. O trabalho com as imagens e o curta é um exemplo disso, centra atenção nas experiências diárias que estão envolvidas nos processos de educação dos sujeitos. Podemos perceber que, para a construção do "O mistério do estuprador" eles usaram como locação espaços de suas circulações cotidianas, de forma que entramos em contato com a visualização do dia a dia destes alunos e dos comportamentos que estão presentes em outros espaços que não é o da sala de aula, como, por exemplo, o tipo de linguagem que utilizam, os códigos de comportamento. Enfim, as imagens nos convidam a olhar para elas para além da trama, o que elas dizem da constituição do cotidiano e circulação destes meninos e como isso ocorre são construções sociais e históricas. As homossexualidades presentes no silêncio do curta estão nesse processo de constituição e relação com o cotidiano dos alunos.

A herança moderna foi responsável por construir a ideia da homossexualidade baseada na doença, no pecado, na inversão, enfim, como algo que deva ser controlado, reprimido e negado. A luta dos movimentos sociais de forma geral, e, especificamente, dos grupos gays, a partir do século XX, serviram para que os sujeitos se afirmassem como sujeitos, visto que ela se organizaria, discursivamente, contra os poderes que o dominam (FERRARI, 2005). E, nesse sentido, o reconhecimento, a experimentação, o compartilhamento e a transformação do desejo em discurso contribuíram para a afirmação dos sujeitos, enquanto sujeitos porque estão "lutando" por meio da vivência, contra a opressão e, enquanto homossexuais, porque estão lutando e se organizando em grupo. Construir uma trama a respeito do estupro de meninos e não trazer nenhum discurso sobre homossexualidades também se organiza nesta mesma lógica, ou seja, não trazer a discussão é uma forma de não reconhecer a vivência e o desejo entre esses meninos e assim, não reconhecerem-se como tais. Diante dessa situação de construção dos sujeitos 
nos moldes do que foi construído na modernidade, o grande desafio que o curta tem como possibilidade seria pensar: como reinventar a vida social e a vida política, problematizar e reinventar a homossexualidade, o desejo, as identidades? A homossexualidade, portanto, não é simplesmente uma atividade sexual de ocupação do corpo, mas, sobretudo, discurso, investigação, conhecimento, criação de significados, troca simbólica, enfim, herdeira legítima da vontade de saber (FOUCAULT, 1988). Mecanismos que ocorrem como investigação e apropriação do próprio corpo e do corpo do outro, que passa pela falta, pelo desejo e pelo prazer. Deste ponto de vista, a homossexualidade está no "O mistério do estuprador" como "não", mas também como uma maneira de afirmar as masculinidades e construir a ideia de estupro. É estupro porque não há permissão, não há desejo, não há busca nem consentimento, de forma que o sentido de estupro se articula ao de masculinidade e de homossexualidade. Tampouco há uma aproximação do estuprador à homossexualidade.

$\mathrm{O}$ que faz esses meninos se aproximarem e experimentarem outros estilos de vida, com toques, trocas afetivas, emoções e sem a ameaça das homossexualidades é a violência de que são todos eles vítimas. É a violência que sofreram que permite o fortalecimento da amizade e da afetividade sem que isso seja utilizado para classificá-los como homossexuais. Segundo Foucault a homossexualidade só foi construída a partir do momento em que não era mais permitida a amizade entre homens. Para que haja a amizade há a necessidade de algum outro aspecto que possibilite os encontros sem a ameaça das homossexualidades. Podem ser os comentários sobre as experiências afetivo-sexuais com meninas, o compartilhamento de gostos comuns e estilizados como típicos das identidades masculinas tais como futebol, carro, lutas e, no caso em que o curta é um exemplo, estarem envolvidos nas mesmas situações de violência, mesmo sendo passivos. Negociam com sentidos das homossexualidades construídos em outro tempo e espaço e que são herdeiros, demonstrando através da produção de suas imagens que são muito mais constituídos por esses discursos do que propriamente produtores deles.

As imagens só são possíveis de serem entendidas e lidas porque elas existem em meio a um processo de trocas de contextos e sentidos e porque negociam com nossas experiências, memórias, histórias de vida, enfim, nos envolvem nessas trocas e nos fazem atribuir significados ao que estamos 
vendo, a construir sentidos para as relações, num processo de mão dupla, de maneira que, ao falar delas, não são mais as imagens que estão falando, mas somos nós. Neste processo de deslocamento entre imagem e nossas constituições, é da cultura que nos constitui que estamos falando, em última instância. Neste sentido, podemos colocar sob suspeita a ação das professoras ao se negarem a dar o primeiro prêmio ao "O mistério do estuprador". As temáticas que a produção trazia como imagem foi mais forte do que a produção em si e mesmo a proposta de avaliação. Podemos pensar que os alunos fizeram perfeitamente o que foi solicitado, ou seja, construíram um curta como foi a proposta de avaliação. Em nenhum momento estava previsto pelas professoras a obrigação de discutir as temáticas dos filmes premiados. Isso nunca tinha acontecido nas outras versões da Mostra. Se eles fizeram o que foi solicitado e não havia expectativa de discussão em torno das temáticas apresentadas, porque não premiar e passar "O mistério do estuprador"? Penso que as professoras entraram neste jogo dos significados e contexto que as imagens e a educação da Cultura Visual estabelecem, um jogo que diz dos processos de hierarquias conceituais. Assim, parece importante dizer que as professoras consideram que temáticas como estupro e de meninos seria algo que não escaparia ileso dos alunos e alunas e que elas seriam "obrigadas" a se colocarem e a entrarem em contato com os seus processos de trocas e de sentidos em negociação com aqueles que surgiriam dos alunos. Talvez o medo seja esse, ou seja, lidar com a imprevisibilidade da sala de aula e que o trabalho com a Cultura Visual que parte dos alunos potencializa. O curta e, portanto, o trabalho com a Cultura Visual que ele possibilita, só ocorre em meio a compreensão desses processos de troca, sentidos e conhecimentos que são capazes de colocar em circulação pelas imagens, entre eles que produzem e iniciam esse processo e os que estarão assistindo e entrando em contato com suas vidas, experiências visuais-educativas, memórias. As professoras entraram neste jogo em que o imaginário social é entendido como aquele que dá sentido, que constrói aquilo que chamamos "realidade". Parece que há uma moralidade e hierarquia cultural no imaginário dessas professoras que é acionado pelas imagens e que determina a ação pedagógica em torno do trabalho com as imagens.

A moralidade cultura é um assunto muito importante para a teoria e a prática da arte/educação. Sem dúvidas, a análi- 
se de representações de gênero e sexualidade normativas e não-normativas (queer), projeta reflexões sobre o impacto teórico e prático que a compreensão destes sistemas visuais e seus discursos teriam na educação da cultura visual. É importante explorar a questão da moralidade dentro da perspectiva do deslocamento histórico da arte/educação para a educação da cultura visual, observando como elas ponderam, compreendem e reconhecem a construção, manutenção, circulação e inclusão de gêneros e sexualidades (DIAS, 2006, p. 114-115).

A citação de Dias adquire um sentido mais forte quando o autor chama atenção para o fato de que do Ensino Básico ao Superior não há uma suficiente discussão em torno da relação entre a construção de gêneros e sexualidades que escape dos discursos religiosos, médicos, morais, mesmo que estas questões estejam cotidianamente sendo representadas, construídas e exploradas nas produções visuais contemporâneas. Essa realidade reflete na sala de aula e organiza a ação das professoras diante do curta. Elas não conseguem ultrapassar a hierarquia e moralidade estabelecida nas nossas licenciaturas e contextos sociais e culturais, de maneira que não entram na proposta dos alunos de tomarem a produção como uma possibilidade de pensar e discutir outros estilos de vida.

\section{Considerações Finais}

"O mistério do estuprador" gerou algo inquietante e mesmo "perigoso" na avaliação das professoras, o que justificou a criação de uma categoria que não existia que foi a premiação como menção honrosa e não como o curta que ganhou o primeiro prêmio. Podemos pensar o que possibilitou que esta produção adquirisse esse caráter perturbador. Arrisco algumas leituras. Por um lado, eles trabalharam em cima de uma liberdade proposta pela escola e que ao mesmo tempo associava com procedimentos que foram capazes de despertar o interesse. A proposta das professoras deixava livre a escolha das temáticas. A única exigência era que produzissem um curta. Era a oportunidade de entrar em contato com algo que era importante para cada um em particular e para o grupo que iriam formar. Houve a necessidade de discutirem e negociarem coletivamente o que iriam produzir. Não era a escola que dizia sobre o que iriam falar, mas o contrário disso. Uma vez escolhida a temática seriam eles que iriam sugerir através de suas escolhas 
o que a turma deveria ver e se não discutir imediatamente, estariam estabelecendo de certa forma, um debate nos corredores, entre eles, com os amigos, enfim, seriam os alunos que iriam sugerir algo para os demais. Podemos pensar que esse processo é quase sempre evitado pelos professores, que tem como uma de suas funções definirem e controlarem o que aparece na sala, algo que parte dos professores para os alunos. "O mistério do estuprador" inverte essa trajetória, mesmo que a proposta tenha partido das professoras. Os alunos ressignificam a proposta e retornam às professores com outra sugestão. Lidar com o que parte dos alunos nem sempre é fácil porque nos coloca em outro lugar nas relações de poder e disputa que é a sala de aula.

Trabalhar em grupo fortalece os alunos nas suas propostas, de forma que essa comunhão entre os meninos faz com que a amizade adquira um caráter subversivo. Esse é um desafio atual para a escola e que o filme nos ajuda a defender, ou seja, a necessidade de recuperar o caráter subversivo da amizade, potencializando-a no sentido de deslocar os sujeitos de suas identidades congeladas e absolutizadas. Quase sempre a escola e os professores caminham no sentido inverso em direção a tirar essa potencialidade da amizade. A construção do curta em torno do fortalecimento da amizade diante da ameaça do estupro possibilitou que esses meninos investissem em outro modo de amizade entre homens, outras formas de serem homens. Uma construção que passou necessariamente pela constituição de imagens desse "novo" homem. Essa foi outra liberdade que entraram em contato a partir da proposta, ou seja, foram chamados a produzirem imagens e a verem imagens de si. Como são capazes de elaborar novas subjetividades, novas formas de existência a partir de um conjunto de regras e de valores estabelecidos não somente pelas professoras, como pela escola e pela cultura. E, ao fazerem isso, também colocam as professoras diante dos seus sistemas de regras e valores, o que faz com que elas decidam não passar o curta. Essa nova forma de existência dos alunos ou que os alunos propõem, esbarra no convite para novas formas de existências das professoras e da escola, que podem ou não aceitar o convite.

Por último, é importante pensar como o trabalho com as imagens e seus desdobramentos podem se situar nesta novidade e, portanto, na liberdade experimentada pelos alunos. Trabalhar com as imagens no chamado a produzi-las desloca os lugares de sujeito, em que são os alunos que propõem as temáticas, diferente de um trabalho com as imagens a partir dos 
professores em que esses últimos elegem de antemão aquelas que serão trabalhadas na sala, de forma a definir a direção das discussões. Em nenhum momento os alunos sentiram dificuldades em lidar com a produção das imagens, demonstrando certa familiaridade com esse tipo de ação. As imagens fazem parte do cotidiano desses alunos, muito embora a escola tenha dificuldade de explorar essa relação com a Cultura Visual, tanto no sentido de solicitar trabalhos com as imagens quanto a dificuldade de colocar essas relações em questão. Mesmo o trabalho solicitado como avaliação concentrou a ação na produção dos curtas, sem levar em consideração a problematização desta relação com as imagens que estão constituindo sujeitos. Este trabalho com as imagens acabou se orientando e servindo a estilização da atitude dos alunos e a estética da existência.

Por estética da existência, há que se entender uma maneira de viver em que o valor moral não provém da conformidade com um código de comportamentos, nem com um trabalho de purificação, mas de certo princípios formais gerais no uso dos prazeres, na distribuição que se faz deles, nos limites que se observa, na hierarquia que se respeita (CASTRO, 2009, p. 150-151).

Investir nessa maneira de existir sem conformidade com os códigos de comportamento é reflexo da liberdade em meio aos jogos de poder, fazendo com que esses jogos possam ser repensados.

Cultura Visual, amizade e homossexualidade estariam em meio a um jogo que nos incita a pensar as relações no interior das escolas e mesmo as relações humanas como atravessadas por poder que não admite a existência de essências nem tampouco de leis transcendentais que definam o que somos e devemos ser. A produção de imagens desses alunos estaria organizada por esse jogo estratégico da amizade em que uns agiriam sobre os outros a partir das imagens, de forma que falar de amizade e de imagens significa colocar em evidência a multiplicidade, intensidade, experimentação e desterritorialização das relações, demonstrando seu caráter provisório e aberto a novas posições de sujeito.

\section{Referências}

CASTRO, Edgardo. Vocabulário de Foucault - Um percurso pelos seus textos, conceitos e autores. Belo Horizonte: Autêntica Editora, 2009. 
DIAS, Belidson. "Acoitamentos: os locais da sexualidade e gêneros na arte/educação contemporânea". In: Visualidades: Revista do Programa de Mestrado em Cultura Visual/ Faculdade de Artes Visuais/UFG. - v. 4, n.1 e 2. Goiânia: UFG, FAV, 2006, p. 101-132.

FERRARI, Anderson. Quem sou eu? Que lugar ocupo? - Grupos Gays, Educação e a construção do Sujeito Homossexual. Tese de doutorado em Educação Unicamp. Campinas: Unicamp, 2005

FOUCAULT, Michel. História das Sexualidades II - O uso dos prazeres. Rio de Janeiro: Edições Graal, 1984. . História das Sexualidades I - A vontade de saber. Rio de Janeiro: Edições Graal, 1988.

. Ditos e Escritos, volume IV - Estratégia, Poder-Saber. Rio de Janeiro: Forense Universitária, 2004.

. El yo minimalista y otras convesaciones. Buenos Aires: La marca editora, 2009.

HERNÁNDEZ, Fernando. "Elementos para una génesis de un campo de estúdio de las prácticas culturales de la mirada y la representación". In: Visualidades: Revista do Programa de Mestrado em Cultura Visual/ Faculdade de Artes Visuais/UFG. - v. 4, n.1 e 2. Goiânia: UFG, FAV, 2006, p. 13-64.

ORTEGA, Francisco. Amizade e estética da existência em Foucault. Rio de Janeiro: Edições Graal, 1999.

Recebido em: 07/10/2013

Aceito em: 08/ 11/2013 


\section{ANDERSON FERRARI \\ aferrariz@globo.com \\ Pós-doutor em Educação e Cultura Visual pela Universidade de \\ Barcelona. Doutor em Educação pela Unicamp. Professor adjunto da \\ Faculdade de Educação da UFJF e professor permanente do PPGE/UFJF. \\ Coordenador do GESED, Grupo de Estudos e Pesquisas em Gênero, \\ Sexualidades, Educação e Diversidade.}

